\title{
Transmissão Geracional Familiar em Adolescentes que Cometeram Ofensa Sexual
}

\author{
Liana Fortunato Costa \\ Universidade de Brasília, DF, Brasil. \\ Maria Inês Gandolfo Conceição \\ Universidade de Brasília, DF, Brasil.
}

\author{
Maria Aparecida Penso \\ Universidade Católica de Brasília, DF, Brasil. \\ Teresa Cristina Othênio Cordeiro Carreteiro \\ Universidade Federal Fluminense, RJ, Brasil.
}

Resumo:Trata-se de uma pesquisa qualitativa sobre a transmissão geracional familiar de quatro adolescentes que cometeram violência sexual contra crianças. O texto enfoca o adolescente em uma perspectiva de interdependência dos adultos responsáveis por sua educação e sobrevivência, pois é sabido que o adolescente que comete ofensa sexual apresenta grandes conflitos em suas relações familiares. O objetivo foi aprofundar o conhecimento sobre essa realidade pouco conhecida em nosso país e tecer uma conexão com a repetição de padrões de violência na vida familiar desses adolescentes, por meio do estudo das dinâmicas familiares. O instrumento utilizado foi o genograma, construído em entrevistas com cada família. Os resultados apontam para relações familiares que reproduzem condições de pobreza da vinculação afetiva, negligência e maus-tratos, pais ausentes e mães autoritárias. A discussão enfoca o processo de transmissão geracional no sentido do cometimento de várias violências que dificultam as condições mínimas de desenvolvimento emocional de seus membros. Em consequência, esses adolescentes acabam por manter relações violentas, mesmo em suas experimentações sexuais iniciais, reproduzindo um padrão presente nas várias gerações. As limitações do estudo referem-se às dificuldades na recuperação dos fatos relativos às histórias familiares, porque, além de valorizarem pouco essas informações, as famílias se queixam do sofrimento que a narrativa traz para todos. Conclui-se que uma proposta de intervenção com adolescente que comete ofensa sexual não pode prescindir da presença da família como protagonista.

Palavras-chave: Abuso sexual, Adolescente ofensor sexual, Transmissão geracional, Genograma. 


\title{
Family Generational Transmission in Adolescents who Committed Sexual Offense
}

\begin{abstract}
This is a qualitative research on family generational transmission of four adolescents who committed sexual violence against children. The text focuses on the adolescent in a perspective of interdependence of the adults responsible for their education and survival, as it is known that adolescents who have committed sexual offense present major conflicts in their family relationships. The objective was to deepen the knowledge about this little known reality in our country and to make a connection with the repetition of patterns of violence in the family life of these adolescents, through the study of family dynamics. The instrument used was the genogram, built in interviews with each family. The results point to family relations that reproduce poverty conditions of affective attachment, neglect and mistreatment, absent parents and authoritarian mothers. The discussion focuses on the process of generational transmission in the sense of committing various forms of violence that hinder the minimum conditions of emotional development of its members. As a result, these adolescents end up in violent relationships, even in their initial sexual experiments, that reproduce a pattern present in the various generations. The limitations of the study refer to difficulties in retrieving facts about family histories because, in addition to valuing this information little, families complain about the suffering that the narrative brings to everyone. It is concluded that a proposal of intervention with adolescents who commit sexual offense cannot dispense the presence of the family as protagonist.
\end{abstract}

Keywords: Sexual abuse, Adolescent sexual offender, Generational transmission, Genogram.

\section{Transmisión Generacional Familiar en Adolescentes que Cometieron Ofensa Sexual}

Resumen: Se trata de una investigación cualitativa sobre la transmisión generacional familiar de cuatro adolescentes que cometieron violencia sexual contra niños. El texto enfoca al adolescente en una perspectiva de interdependencia de los adultos responsables de su educación y supervivencia, pues es sabido que el adolescente que cometió ofensa sexual presenta grandes conflictos en sus relaciones familiares. El objetivo fue profundizar el conocimiento sobre esa realidad poco conocida en nuestro país y establecer una conexión con la repetición de patrones de violencia en la vida familiar de esos adolescentes, a través del estudio de las dinámicas familiares. El instrumento utilizado fue el genograma, construido en entrevistas con cada familia. Los resultados apuntan a relaciones familiares que reproducen condiciones de pobreza de la vinculación afectiva, negligencia y malos tratos, padres ausentes y madres autoritarias. La discusión enfoca el proceso de transmisión generacional en el sentido de la comisión de varias violencias que dificultan las condiciones mínimas de desarrollo emocional de sus miembros. En consecuencia, esos adolescentes acaban por mantener relaciones violentas, incluso en sus experimentos sexuales iniciales, que reproduce un patrón presente en las distintas generaciones. Las limitaciones del estudio se refieren a las dificultades en recuperar hechos relativos a las historias familiares, porque, además de valorar poco esas informaciones, las familias se quejan del sufrimiento que la narrativa trae para todos. Se concluye que una propuesta de intervención con el adolescente que comete ofensa sexual no puede prescindir de la presencia de la familia como protagonista.

Palabras claves: Abuso sexual, Adolescente ofensor sexual, Transmisión generacional, Genograma. 
Este texto tem por objetivo conhecer e discutir a transmissão geracional de padrões violentos de relações em famílias de adolescentes que cometeram ofensa sexual, por meio do estudo do genograma. Cada vez mais se dá valor e ênfase à compreensão das influências do contexto familiar sobre a realidade do cometimento de ato violento de natureza sexual (Conceição, Penso, Costa, \& Carreteiro, 2014; Lansford et al., 2007; Lauritsen, \& Carbone-Lopez, 2011; Marshall, 2001; Penso, Costa, Conceição, \& Carreteiro, 2013; Rodgers \& McGuire, 2012; Worley, Church, \& Clemmons, 2011; Zankman, \& Bonomo, 2004). O genograma, por ser um instrumento de avaliação e intervenção da dinâmica familiar (McGoldrick, Gerson, \& Petry, 2012), constitui-se numa excelente ferramenta para tratar do tema. Sendo assim, este estudo tem por objetivo conhecer a dinâmica de famílias com histórico de violências sexuais praticadas por adolescentes, na busca de aprofundar o conhecimento sobre essa realidade ainda muito pouco conhecida em nosso país, bem como estruturar uma conexão com a repetição de padrões de violência na vida familiar desses adolescentes. Encontram-se estudos dessa abrangência, baseados na aplicação do genograma como instrumento de avaliação, ou no estudo da influência geracional transmitida pela família, e em situações de adolescentes autores de ato infracional, em Cenci, Teixeira e Oliveira (2014) e Santos, Marin e Castoldi (2013). Esses estudos corroboram a propriedade do fundamento e propósito do texto agora apresentado.

\section{$O$ adolescente que cometeu ofensa sexual, sua família e o contexto social}

Assume-se aqui uma concepção de que o adolescente se encontra numa relação de interdependência dos adultos responsáveis por sua educação e sobrevivência. Reconhece-se a condição peculiar do adolescente por estar em fase de desenvolvimento, tanto do ponto de vista físico, psíquico e emocional (Penso, \& Costa, 2017), como do ponto de vista jurídico (Machado, 2003). Essa concepção implica ver o adolescente como um sujeito em processo de amadurecimento, que se caracteriza por vivências e experiências exploratórias (sexuais ou não), além de demandar que tenha seus direitos valorizados e respeitados (Brasil, 1990). A violência sexual é uma questão de saúde pública e deve ser enfrentada tanto social como individualmente, na medida em que se ofereça aten- ção e espaço para que os ofensores sexuais, adultos e adolescentes, sejam atendidos, orientados e tratados em suas especificidades (Meneses, Stroher, Setubal, Wolff, \& Costa, 2016).

A referência ao adolescente que cometeu ofensa sexual alinha-se à perspectiva adotada pelo pesquisador Chagnon (2012), que considera o abuso sexual como uma decorrência de práticas educativas violentas e de conflitos com a autoridade. Esse autor destaca que a ofensa sexual praticada por adolescentes está associada à dificuldade destes em lidar com a autoridade paterna, uma vez que pertencem a famílias nas quais as interações são pautadas por relações agressivas e práticas educativas que mais agridem do que orientam e/ou supervisionam. Outros autores (Costa, \& Costa, 2014; Letourneau, \& Miner, 2005; Marshall, 2001; Oliver, 2007; Rodgers, \& McGuire, 2012; Roman, 2012) reconhecem que esses adolescentes não podem ser classificados como "portadores de patologia", apesar de terem sido violentos, e enfatizam o papel da família e das circunstâncias sociais na configuração dessas violências. Atualmente, já se tem uma pequena, porém representativa, amostra de autores nacionais que pesquisam e concordam com essa perspectiva (Costa, Costa, \& Conceição, 2014; Costa, Marreco, Barros, \& Chaves, 2015; Penso et al., 2013; Pincolini, \& Hutz, 2014).

No que tange ao contexto social, estudos realizados na região Centro-Oeste e na região Sul do país indicam que políticas sociais de distribuição de lotes auxiliam na configuração de várias famílias que residem em um único lote (às vezes até quatro famílias), onde as crianças e adolescentes permanecem sem cuidado e supervisão de adultos, ainda que fiquem limitados ao perímetro do terreno (Costa, Junqueira, Meneses, \& Stroher, 2013; Costa et al., 2015; Pincolini \& Hutz, 2014). Essa estruturação de moradia facilita o surgimento de violência sexual, visto que os adolescentes são os responsáveis pelo cuidado e proteção de outras crianças, compondo um quadro de dependência e intimidade entre crianças e adolescentes.

No entanto, necessário se faz ampliar a compreensão dessas famílias procurando apontar o contexto sociopolítico mais amplo de pobreza, que é permeado por violações de direitos básicos (moradia, transporte, saúde, trabalho), ausência de políticas de proteção à criança e ao adolescente, como creches, escola com tempo integral, atividades complementares à 
escola, saúde de qualidade (Spilbury, \& Korbin, 2013). Tais situações fazem com que crianças e adolescentes necessitem ficar sob a responsabilidade de terceiros (vizinhos, conhecidos, parentes) e que os próprios irmãos tenham que cuidar uns dos outros (Pincolini, \& Hutz, 2014). Vale ressaltar que, segundo dados da Pesquisa Nacional por Amostra de Domicílios (Instituto Brasileiro de Geografia e Estatística, 2015), o Distrito Federal, contexto do estudo em tela, tem o pior índice de distribuição de renda e a maior concentração de renda do país.

Nessa esteira, inúmeras evidências científicas apontam uma forte e consistente associação entre desigualdade social e violência, o que já foi demonstrado em vários períodos da história e configurações diferentes (Wilkinson, \& Pickett, 2010). Esses autores salientam que as sociedades desiguais sofrem mais violência, mas que, se a desigualdade for diminuída, os níveis de violência também diminuem. Embora o contexto socioeconômico sem dúvida tenha impacto contundente na produção da violência (Turner, Shattuck, Finkelhor, \& Hamby, 2016), o interesse, neste texto, é tratar especificamente das dinâmicas que se operam no interior das famílias, e ao longo das gerações, reeditando padrões pautados por códigos de violência.

\section{A transmissão geracional}

A família é um lugar privilegiado de transmissão da cultura, sendo este um processo fundamental para a constituição do sujeito. A transmissão geracional torna-se evidente por meio da repetição dos padrões familiares. É por meio dessa transmissão que se garantem a sobrevivência e a perpetuação da família (Almeida, Magalhães, \& Féres-Carneiro, 2014). O estudo do processo de transmissão geracional, proposto originalmente por Bowen (1991), enfoca a importância do conhecimento da história familiar ao longo das gerações. Para esse autor, ocorre a transmissão dos níveis de diferenciação do self familiar, por meio das gerações múltiplas, conduzindo as dificuldades de cada um para além do indivíduo e de sua família nuclear, por várias gerações passadas. A configuração atual da família é um subsistema emocional reagindo aos relacionamentos passados (McGoldrick et al., 2012).

Numa perspectiva sistêmica, a família é compreendida como a "matriz de identidade", que envolve os processos de separação e pertencimento, que atu- alizam as regras e os padrões de relacionamento dos diferentes sistemas familiares de origem, ao longo do ciclo de vida familiar e da história transgeracional (Minuchin, Nichols, \& Lee, 2009). Nesse processo, é delegado a cada membro da família um papel e um destino específicos, cujo cumprimento vai depender das lealdades familiares, definidas por Boszormenyi-Nagy e Spark (2001) como uma trama motivacional, tipicamente dialética, de raízes multipessoais, que implica a existência de expectativas estruturadas de grupo, no qual todos os membros adquirem um compromisso com forte componente de obrigação ética. Isso significa que cada membro da família nasce com uma missão a ser realizada ao longo da vida. De acordo com Gaulejac, Marquez e Ruiz (2005), com relação aos filhos, existe um projeto parental para cada um, mesmo antes do seu nascimento, em uma cadeia de transmissão que ultrapassa as gerações.

As lealdades familiares são organizadas a partir dos mitos familiares, que estão presentes em todas as famílias e que constituem "a liga" que proporciona ao grupo familiar um sentido de identidade (Neuburger, 1997). Portanto, o mito define as regras, as crenças e os papéis dentro da família, ditando a sua forma de funcionamento e mantendo a sua coesão. Bowen (1991) propôs uma organização gráfica das informações sobre a família em diferentes gerações, à qual denominou de genograma. Esse é um instrumento utilizado não só pelos terapeutas de família e pesquisadores da dinâmica familiar, mas também por outros profissionais da área de saúde que trabalham com crianças, adolescentes e adultos. McGoldrick et al. (2012) acreditam que a justificativa para a grande utilização do genograma deve-se ao fato de que esse instrumento permite uma avaliação e intervenção simultâneas, sendo um método eficiente para obter informações sobre a família, fornecendo uma representação dos laços transgeracionais e intergeracionais.

A transmissão psíquica geracional refere-se ao material psíquico da herança genealógica não transformada e não simbolizada que apresenta lacunas na transmissão, de modo que o significado não simbolizado, ou fato psíquico inconsciente, atravessa diversas gerações (Correa, 2000). As mudanças e fissuras nos sistemas de transmissão psíquica colocam em evidência a parte negativa da transmissão, o oculto, o não dito, permeando várias gerações. Estudos suge- 
rem que a violência é aprendida por meio da transmissão geracional (Barreto, Bucher-Maluschke, Almeida, \& Souza, 2009), a partir da reprodução do modelo de educação recebido dos pais na infância, resultando numa perpetuação transgeracional do ciclo da violência. Há quem defenda que o não dito ou o segredo pode funcionar como estratégia inconsciente dos pais para preservar e proteger a vida psíquica de gerações seguintes (Salina, 2015). Com relação ao adolescente que cometeu ofensa sexual, é inequívoca a associação feita por pesquisadores entre as práticas educativas violentas, o padrão violento da interação familiar e o cometimento do ato violento (Chagnon, 2012; Costa et al., 2013; Lansford et al., 2007; Zankman, \& Bonomo, 2004).

\section{Método}

Trata-se de um recorte de uma pesquisa qualitativa que tem como objetivo produzir conhecimento sobre o adolescente que cometeu ofensa sexual, bem como sobre as interações familiares de sua família de origem. O contexto no qual se teve acesso aos adolescentes foi uma intervenção psicossocial oferecida em uma instituição da Secretaria de Saúde do Distrito Federal, que é uma referência regional no circuito de proteção às crianças e adolescentes em situação de violência sexual. Essa intervenção grupal consiste em duas etapas. A primeira etapa consiste em uma entrevista com cada família na qual se busca obter informações socioeconômicas da família, bem como dados pessoais de cada membro, conhecer a história da violência sexual ocorrida, a dinâmica das interações familiares e a inserção do adolescente no sistema de justiça, ou seja, se já houve ou não a notificação da violência. Todos os membros da família, inclusive o adolescente que cometeu a ofensa sexual, são convidados a comparecer. A segunda etapa é o oferecimento da intervenção propriamente dita, que consiste em sete sessões de grupo, nas quais os adolescentes são atendidos em família, ou seja, os adolescentes e todos os membros da família comparecem a todas as sessões. A intervenção grupal também oferece oportunidades para que os adolescentes sejam vistos em um agrupamento individual no qual não estão presentes os demais membros da família. A intervenção é conduzida por profissionais da instituição, quatro psicólogas e uma assistente social. A Tabela 1 apresenta informações sobre as idades dos adolescentes, com quem vivem, renda familiar, e quem foi a vítima. Para garantir o anonimato e a confidencialidade, os participantes aqui serão identificados com as letras A, B, C e D. Toma-se como referência a orientação do Estatuto da Criança e do Adolescente (Brasil, 1990) para a condição de adolescente, com idade entre 12 e 18 anos. As idades dos adolescentes na tabela são aquelas no momento da intervenção.

O instrumento escolhido foi o genograma, por propiciar uma via de acesso às questões da dinâmica familiar em situação de violência sexual, por meio do levantamento de informações que identificam a qualidade das interações familiares em duas a três gerações. A confecção do genograma (McGoldrick et al., 2012), representação gráfica dos membros da família, de suas várias gerações e da qualidade dessas relações atuais e passadas, buscou conhecer a repetição dos atos violentos em cada geração. Cada genograma foi construído juntamente com todos os membros da família presentes na entrevista, que foi conduzida por um profissional. Essas entrevistas tiveram duração aproximada de uma hora e meia, não tendo sido gravadas, e sim escritas, e essas anotações se constituíram a base para a interpretação das histórias familiares. Essa configuração deve-se ao fato de que na instituição, as pesquisas são realizadas com mediação do profissional responsável pelo cliente, não sendo possível o pesquisador ter acesso ao cliente de forma direta.

\section{Tabela 1}

Informações sobre os participantes.

\begin{tabular}{|c|c|c|c|}
\hline $\begin{array}{l}\text { Adolescente } \\
\text { que cometeu } \\
\text { o abuso }\end{array}$ & Vive com & Renda & Vítima \\
\hline A - 16 anos & Avó & $2 / 3 \mathrm{sm}$ & $\begin{array}{c}\text { Uma } \\
\text { adolescente do } \\
\text { sexo feminino }\end{array}$ \\
\hline B - 16 anos & Mãe & $2 / 3 \mathrm{sm}$ & $\begin{array}{c}\text { Duas crianças } \\
\text { do sexo } \\
\text { feminino }\end{array}$ \\
\hline C - 12 anos & Mãe & $2 / 3 \mathrm{sm}$ & $\begin{array}{l}\text { Uma criança do } \\
\text { sexo masculino }\end{array}$ \\
\hline D - 15 anos & $\begin{array}{c}\text { Mãe, } \\
\text { padrasto, } \\
\text { irmãos }\end{array}$ & $4 / 5 \mathrm{sm}$ & $\begin{array}{c}\text { Quatro crianças } \\
\text { do sexo } \\
\text { masculino e } \\
\text { feminino }\end{array}$ \\
\hline
\end{tabular}

sm: salário mínimo. 


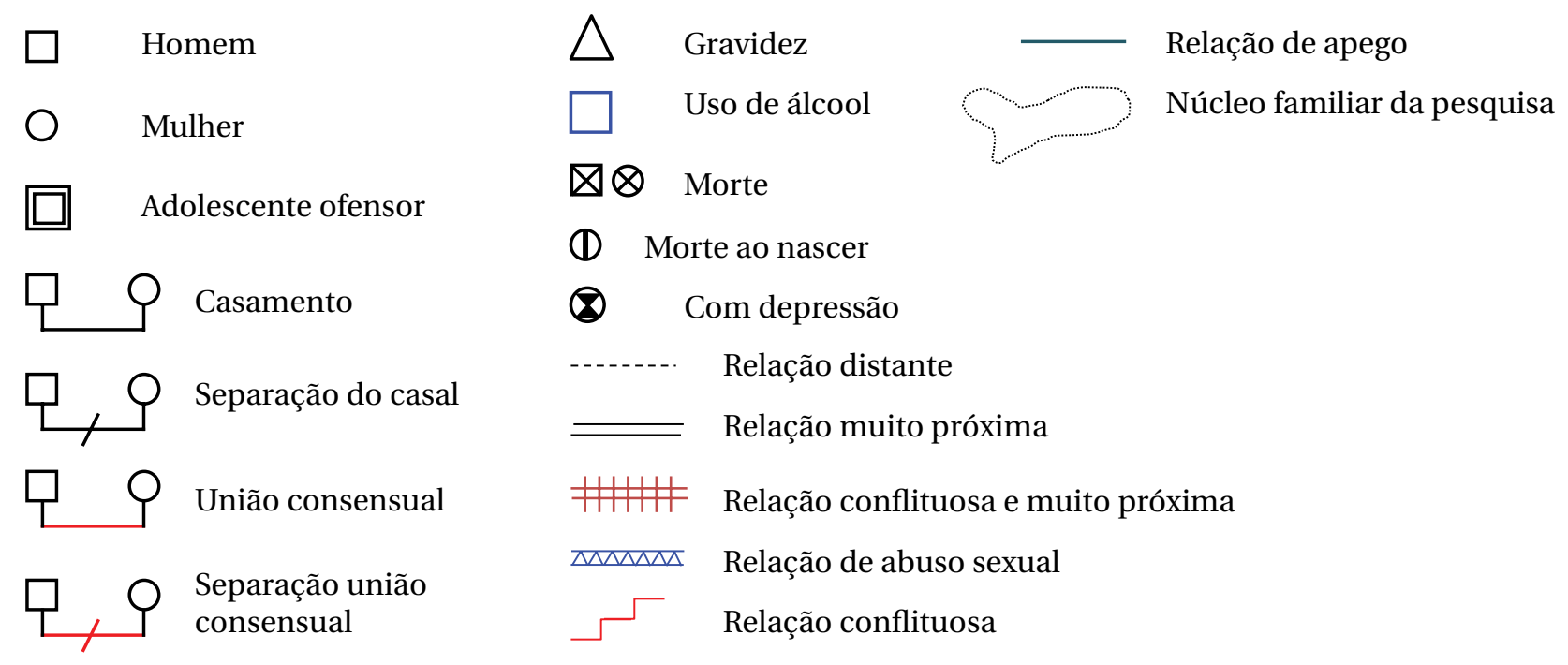

Figura 1

Símbolos do genograma.

A construção do genograma pressupõe a utilização de alguns símbolos, apresentados na Figura 1

A análise das informações seguiu a orientação de Minayo (1996), que sugere uma análise de conteúdo por meio de uma leitura flutuante do texto, a construção de núcleos de sentido, a partir dos quais se faz a interpretação e a discussão dos dados. A análise levou em conta as falas e as interações observadas durante a aplicação do genograma, bem como a construção gráfica em si. A pesquisa foi inscrita no Comitê de Ética da Fundação de Ensino e Pesquisa em Ciências da Saúde (Fepecs) da Secretaria de Estado de Saúde do Distrito Federal e aprovada com o Parecer no 331/2009, com Emenda aprovada em 4 de agosto de 2014.

\section{Resultados}

A seguir, serão apresentadas as quatro famílias participantes do estudo e os seus respectivos genogramas.

Família 1 - O pai do $A$ teve seu filho muito cedo, aos 16 anos de idade, fruto de um breve relacionamento com a mãe de $A$, que era mais velha e trabalhava como empregada doméstica em sua casa. Eles nunca chegaram a morar juntos e quem criou $A$, até os 11 anos de idade, foi sua avó paterna. Essa avó é a figura central desta família, reunindo todos os filhos e netos ao seu redor. Todos moram perto dela e é ela quem decide sobre as férias, os passeios e, nos finais de semana, faz questão do almoço em família. $A$ tem pouco contato com sua mãe e uma relação bem próxima com sua avó paterna. A sua madrasta é irmã de sua mãe e sua madrinha. Seu pai já está com ela há cerca de 10 anos, possuem um filho e ela está grávida de outro. A mãe de $A$ teve mais três filhos, dois meninos e uma menina. Os filhos homens vivem com seus pais em outro estado, e sua mãe só ficou com uma filha de 12 anos, porque esse pai não quis levá-la com ele. Atualmente, a mãe está morando com outro companheiro. Ao todo, ela teve quatro companheiros. $O$ relacionamento do pai com $A$ passou a existir, de fato, há mais ou menos quatro anos e que existe uma grande dificuldade de se falar de afetos, de conversar, apesar de o filho saber que este pai gosta muito dele. A participou como observador de um estupro coletivo de uma adolescente no banheiro da escola. Com relação à Figura 2 do genograma, observam-se vários relacionamentos conjugais rompidos, que estão apontados, nas duas gerações, por linhas vermelhas cortadas por um traço inclinado, indicando separação conjugal daquela díade. A linha preta com pontilhado maior indica a existência de conflito (distanciamento afetivo da mãe em relação aos filhos). A linha preta com pontilhado menor indica que a rede familiar de $A$ se compõe pela tia (madrinha/madrasta) e os membros da família do pai (avós paternos, pai, irmãos por parte do pai e da tia/madrasta), sendo que a mãe se encontra fora dessa rede. Além disso, o adolescente $A$ mantém contato somente com três de seus seis irmãos, perdendo recursos de sua rede fraterna.

Família 2 - A mãe de $B$ saiu de casa com 11 anos de idade para ser empregada doméstica e cuidar de 


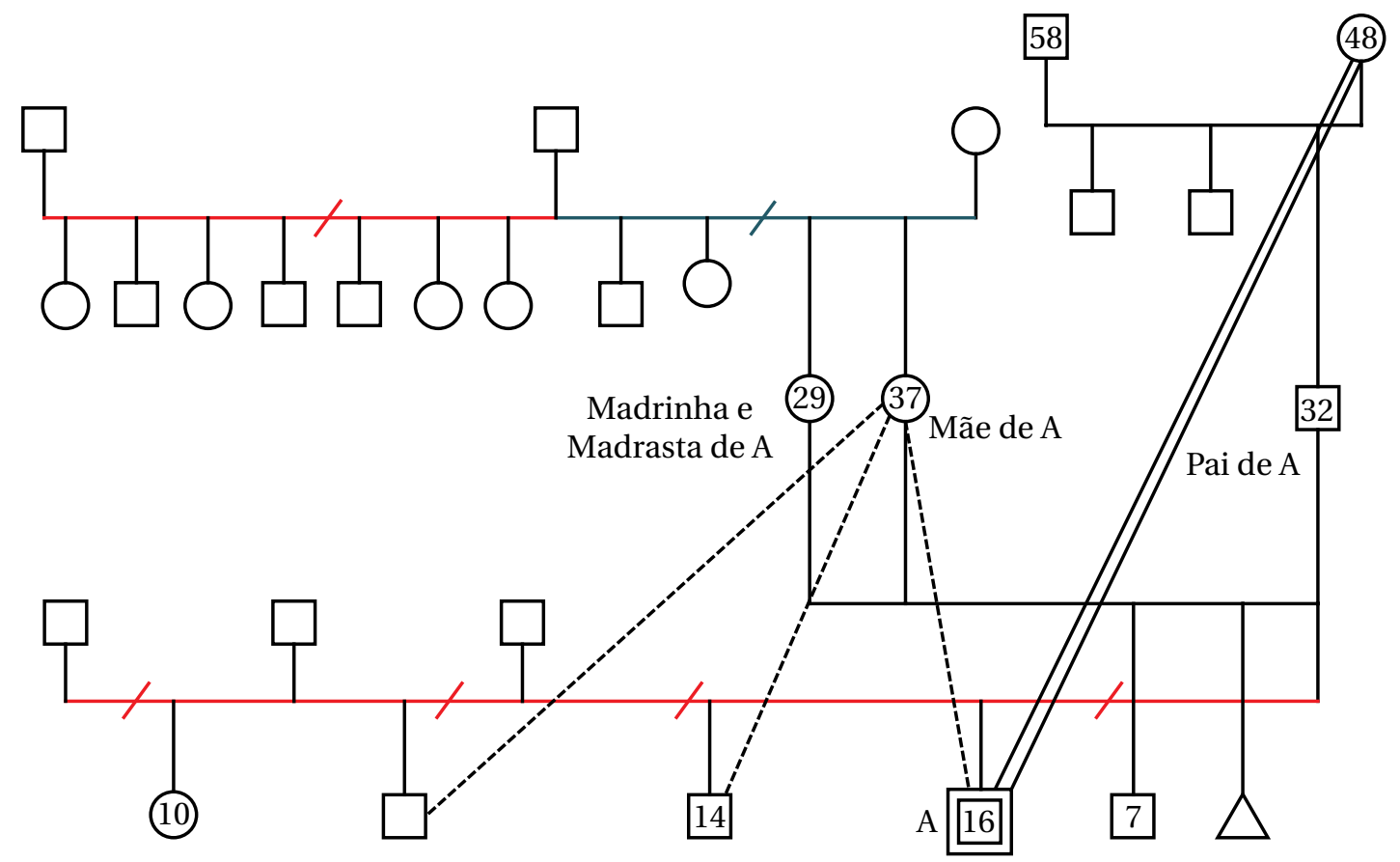

Figura 2

Genograma da Família 1.

crianças. Ela teve cinco filhos. A primeira filha foi fruto de um relacionamento sem importância. Essa filha vive com a avó materna em outro estado, desde o seu primeiro ano de vida. $B$, segundo filho, foi fruto de um relacionamento de um ano com uma pessoa que gostava de bebida, farra e mulheres. Os pais de $B$ nunca chegaram a morar juntos. A mãe relata ter sofrido muito nessa gravidez e quem a apoiou foi o padrinho de $B$, que a levou para morar e trabalhar com ele. $B$ não possui contato com o pai biológico. Após o nascimento dele, a mãe passou a ter um relacionamento com o pai de sua terceira filha, que também bebia e gostava de farra. Esse relacionamento durou quatro anos. Hoje, ela vive com seu atual companheiro, que, segundo ela, é o homem ideal, pois não bebe, trabalha e ajuda em casa. Com esse atual companheiro, a mãe de $B$ teve duas filhas, sendo que a mais nova morreu ao nascer. A mãe de $B$ relata que sua própria mãe (ou seja, a avó de $B$ ) sofreu muito com seu pai (avô de $B$ ), que era uma pessoa trabalhadora, porém bebia muito e se alterava, chegando a bater e brigar muito com os filhos e a mulher. A mãe de $B$ relata não ter raiva de seu pai e guardar na memória a lembrança dele tocando violão e a mãe cantando, numa roda com todos os irmãos. Chama a atenção o fato de que nesta família o "ato de beber" era um ato que unia e, ao mesmo tempo, afastava todos. O pai de $B$ sempre que estava com eles, nas horas livres, bebia e brincava com os filhos. Porém, quando ele se alterava, a sua esposa saía com todos os filhos e os levava para dormir ao relento, evitando com isso que ele maltratasse algum filho. A mãe dá a esta família, durante a realização do genograma, o nome de Encontro de Afetos ("onde a gente procura um colo!') e relata que quer muito ter a sua casa própria pronta para poder sempre reunir todos os filhos. A mãe de $B$ repete a história de sua própria mãe, na dificuldade de falar, de conversar com os filhos. A denúncia envolvendo $B$ diz respeito ao abuso de duas meninas, uma que sua avó cuidava em casa (sobrinha do seu padrasto) e a outra na casa do pai. A denúncia surgiu da mãe da última criança vítima que flagrou $B$ no banheiro com sua filha.

A Figura 3 do genograma informa a presença de várias relações rompidas (cortes nas linhas vermelhas) e relações conflituosas entre gerações diferentes e na mesma geração (linha sinuosa vermelha e azul), bem como uma relação conflituosa e próxima (linha dupla com traços). Outro fator importante é o relato de vários membros da família fazendo uso de bebida com exagero, e a linha preta que reúne em uma relação mais constante várias pessoas em conflito. 


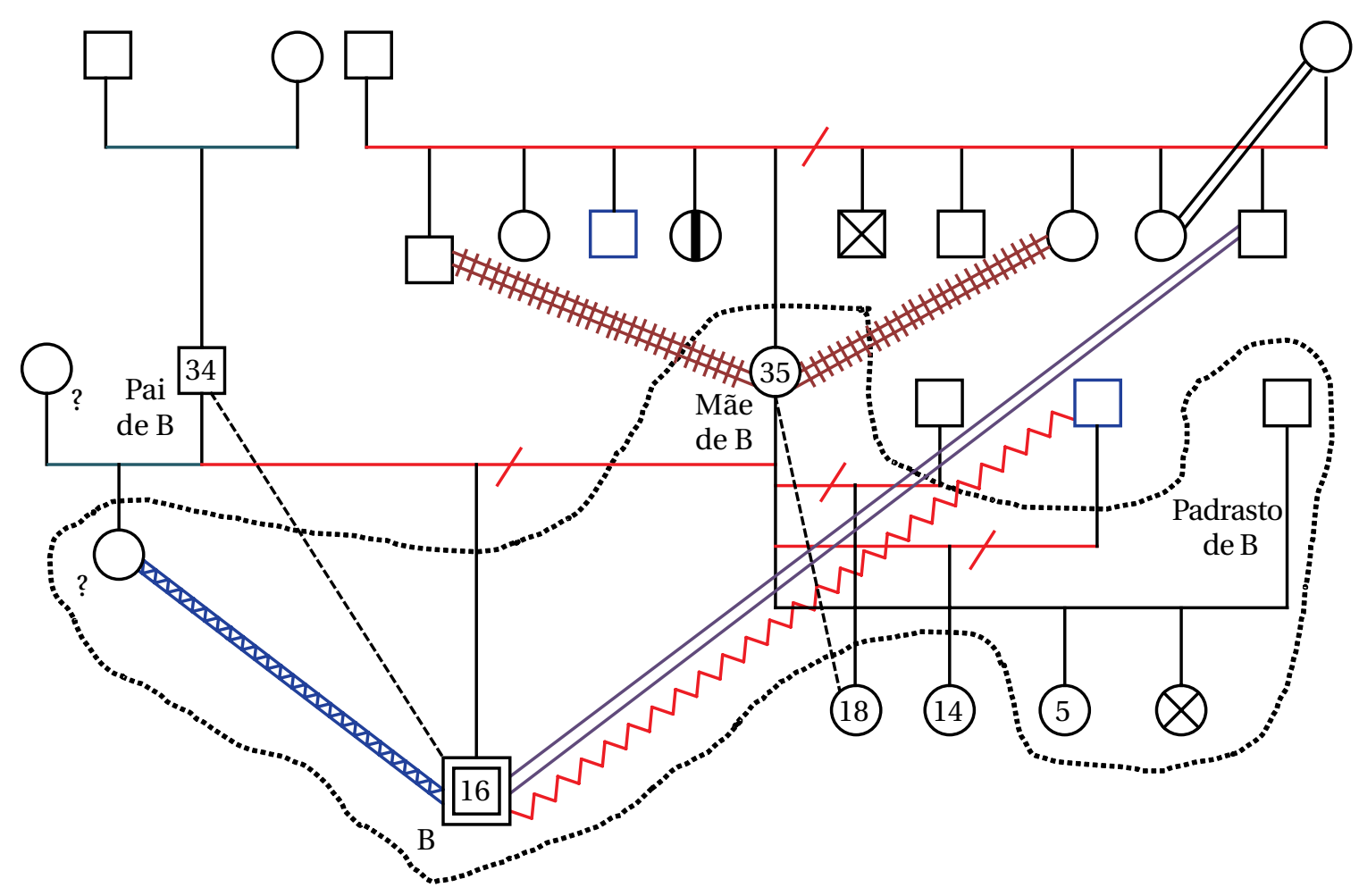

Figura 3

Genograma da Família 2.

Família 3 - $C$ nasceu quando sua mãe tinha 15 anos. O pai dele tinha 17 anos na época. Eles ficaram juntos por seis anos e tiveram outro filho, hoje com 9 anos. A mãe relata que o relacionamento não deu certo porque o pai de $C$ era muito farrista e mulherengo. Ele foi assassinado numa rodovia por causa de ciúmes de outra mulher, que não era sua esposa, há três anos. $C$ soube de tudo, inclusive detalhes do assassinato e a causa. $C$ relata sentir muita falta do pai. A mãe dele vive com o atual companheiro, com quem teve duas filhas, sendo que uma delas nasceu prematura e faleceu com seis dias de vida. O pai de $C$, na época de seu assassinato, estava casado e tinha mais dois filhos com a esposa. A avó paterna é uma figura importante para $C$, que, embora more longe, o visita a cada 15 dias. $C$ abusou de uma criança de sexo masculino, seu vizinho. Ele relata que também viu cenas de abuso no banheiro de sua escola e não denunciou por medo. Observa-se no genograma (Figura 4) vínculos rompidos, violência presente sob a forma de assassinato e apego do adolescente ao pai que foi assassinado.

Família 4 - Os avós de $D$ casaram-se cedo e, por meio de muito trabalho, construíram um patrimônio que resultou em uma fazenda. Eles permaneceram casados por 65 anos. Os filhos perderam tudo o que os pais haviam construído, porque brigavam muito e alguns nem se falavam. A mãe de $D$ teve sérios conflitos familiares: foi criada pelos avôs paternos; era muito agressiva quando menina; fugiu de colégio interno; e engravidou de $D$ quando tinha 15 anos, quando saiu de casa para morar com as tias. $D$ não tem contato com seu pai biológico. Depois do nascimento de $D$, sua mãe conheceu outro homem com quem teve dois filhos, hoje com 12 e 9 anos, respectivamente. O lema da família é: "Brigar pode, conversar não”. O padrasto de $D$ é caminhoneiro, só aparece em casa nos finais de semana e permanece sem conversar com ninguém. Por outro lado, a mãe de $D$ dorme muito durante as tardes, todos os dias e tem histórico de depressão. $D$ desde pequeno teve grande rotatividade de lugares que o acolheu: sua avó, outros familiares e abrigos. $D$ tem histórico de maltratar animais e abusou sexualmente do irmão de 9 anos de idade e de outras três crianças. O genograma (Figura 5) apresenta uma informação que é um losango dentro de um círculo (membro do sexo feminino) ou dentro de um quadrado (membro do sexo masculino), repre- 


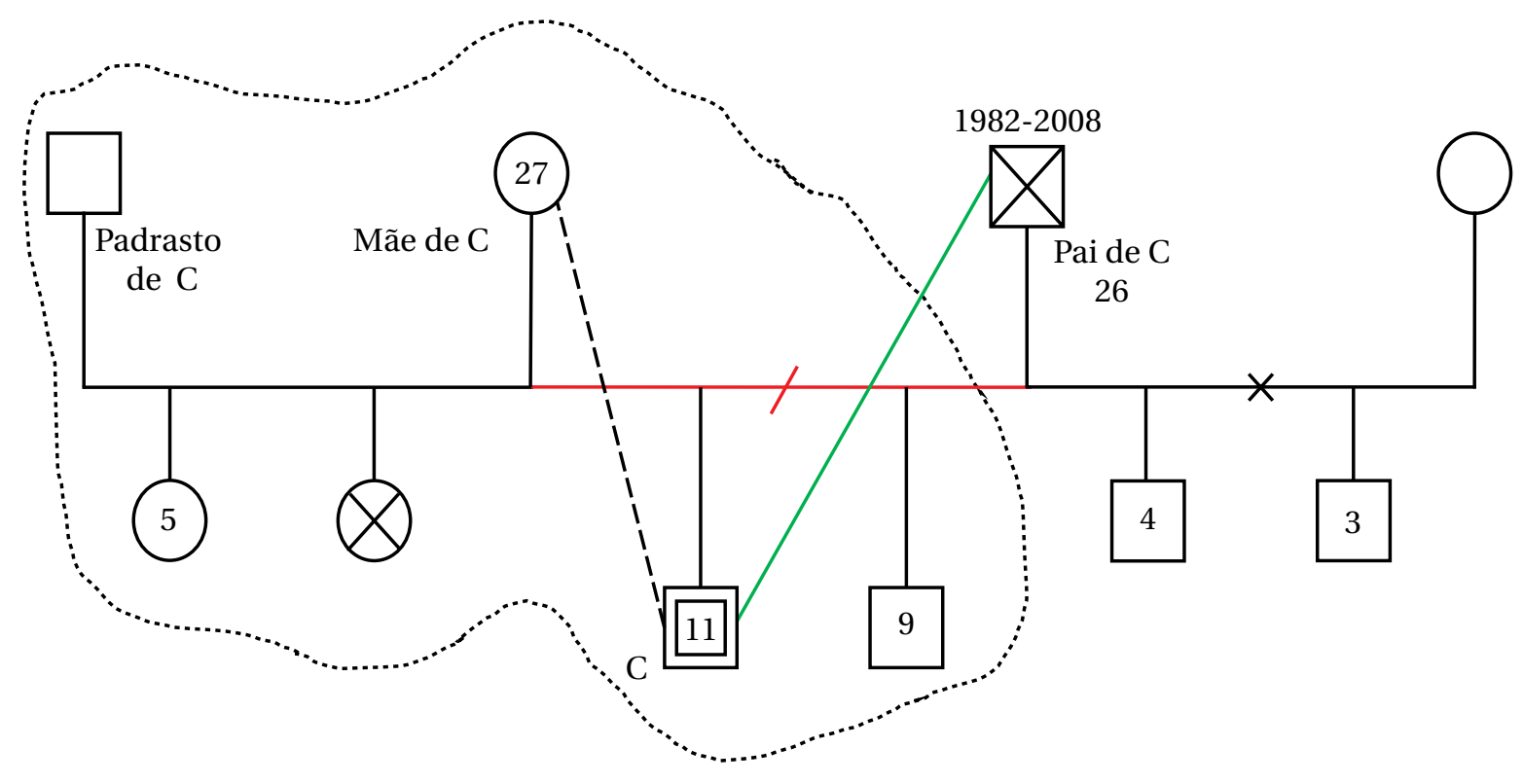

Figura 4

Genograma da Família 3.

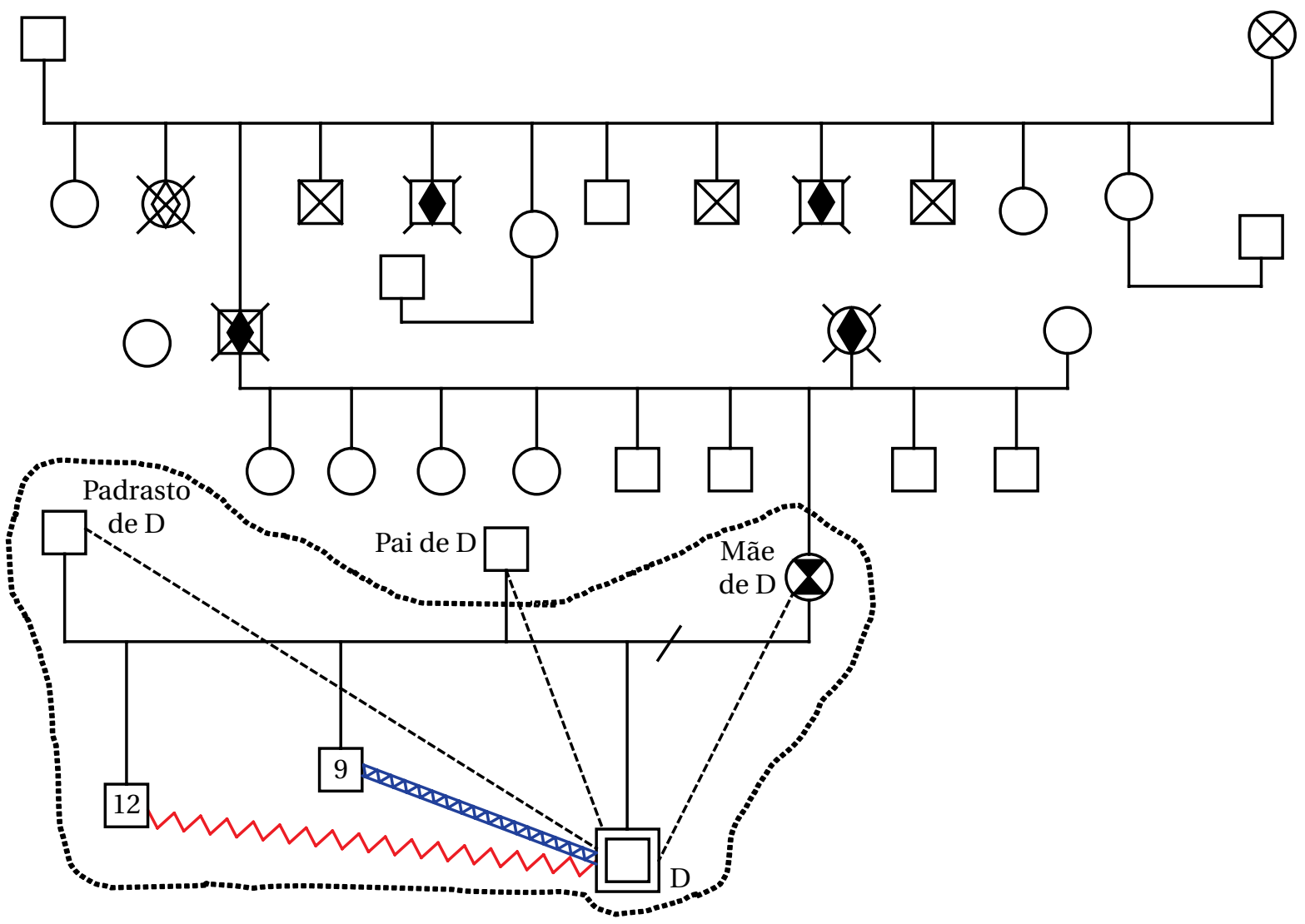

Figura 5

Genograma da família. 
sentando pessoas com comportamentos de extremo conflito com outros membros da família, e que resultaram em brigas e rompimentos afetivos. O que chama muito a atenção é que todos os indicativos de graves conflitos estão centrados na geração do adolescente, mostrando que sua rede de apoio está bastante empobrecida, em função do afastamento com as gerações anteriores.

\section{Discussão}

As histórias, ainda que narradas de maneira simplificada e com possíveis lapsos de informações, apresentam aspectos em comum e permitem a construção de núcleos de sentido. É importante salientar que a história da família foi obtida a partir da narrativa do responsável presente na entrevista (mulheres), pois não houve comparecimento de nenhum genitor dos adolescentes. Os núcleos de sentido organizados foram: 1) A pobreza das relações afetivas e a falta do projeto parental; 2) A negligência e os maus-tratos; 3) Pais ausentes e mães dominadoras e sem investimento afetivo no adolescente; e 4) A transmissão geracional. Organizou-se o conteúdo em discussão que se refere aos vários círculos concêntricos que circundam o adolescente: ele próprio; seu contexto imediato, a família; e o contexto seguinte, seu entorno sociocomunitário.

\section{Núcleo de sentido 1 - A pobreza das relações afetivas e a falta do projeto parental}

Os adolescentes aqui apresentados possuem pouco ou nenhum contato com o pai biológico ou com outra figura masculina que poderia ter uma função de autoridade em suas vidas, aspecto preponderante na configuração familiar de sujeitos com essa idade e, em particular, de adolescentes com condutas sexuais agressivas (Marshall, 2001; Minuchin et al., 2009; Roman, 2012). $B$ tem contatos esporádicos com o pai, $D$ não teve contato com o pai biológico e $C$ teve o pai assassinado quando ainda criança. $A$ só passou a ter contato com o pai biológico há cerca de quatro anos. A diferença entre autoridade e autoritarismo é muito relevante na explosão dos atos violentos sexuais no contexto intrafamiliar, pois o adolescente necessita de uma relação com autoridade para conter e/ou redirecionar suas angústias, e não de uma relação de coerção que pode aumentar seu isolamento e compor um quadro de sintomas depressivos (Chagnon, 2012; Rodgers \& McGuire, 2012).

Do mesmo modo que há um vácuo de autoridade, há também ausência de vinculação afetiva importante com as figuras parentais e nem mesmo a mãe consegue compor essa condição, pois se apresenta em uma relação inconstante e pobremente interessada pelo adolescente. $A$, por exemplo, foi criado pela avó materna; $B$ mora com a mãe, mas esta tem dificuldades de conversar com os filhos; a mãe de $D$ sofre de depressão, passando todas as tardes deitada e sem contato com os filhos. Os estudos de adolescentes que cometeram ofensa sexual dão importância ao aspecto da vinculação afetiva, pois esta constitui um recurso de possibilidades de prevenção da reincidência do ato violento, além de oferecer um apoio e sentimento de pertencimento ao grupo familiar (Costa \& Costa, 2014; Lauritsen, \& Carbone-Lopez, 2011; Marshall, 2001; Rodgers, \& McGuire, 2012). Nas histórias dos adolescentes desta pesquisa, observam-se fragilidade na vinculação afetiva e também a ausência de uma vinculação afetiva constante. Assim, os adolescentes se desenvolvem sem um projeto parental, ou seja, sem um investimento afetivo emocional por parte do pai ou da mãe e sem a delegação de um papel específico e um lugar na família que facilitem o processo de identificação (Chagnon, 2012; Penso, Conceição, Costa, \& Carreteiro, 2012; Worley et al., 2011).

A falta de autoridade e a presença do autoritarismo ainda se expressam na condição de que os adolescentes são responsáveis pelo trabalho doméstico, concretizando no lar um conflito de hierarquia, pois são colocados em uma posição de dominação como se fossem "serviçais", sendo-lhes dada uma falsa autoridade para cuidar das crianças, na medida em que podem ter poder momentâneo sobre elas. Desse modo, são dominados e atuam dominando outras crianças por meio da violência sexual (Costa et al., 2015; Oliver, 2007; Penso et al., 2012; Pincolini \& Hutz, 2014). Considera-se que os adolescentes têm em comum a experiência de pertencerem a grupos familiares com presença de rompimentos de laços afetivos nas várias gerações, relações afetivas frágeis em uma mesma geração. Todos esses aspectos são considerados como vivências violentas e promotoras de condutas violentas que poderão surgir mais adiante em etapas do desenvolvimento do adolescente (Bogaerts, Buschman, Kunst, \& Winkel, 2010; Chagnon, 2012; Finkelhor, Ormrod, Turner, \& Holt, 2009). 


\section{Núcleo de sentido 2 - A negligência e os maus tratos}

Os adolescentes, ainda, foram negligenciados, não recebendo cuidados de um responsável constante na infância, além de passarem de casa em casa, convivendo com outras pessoas que não assumiam seus cuidados de forma permanente. Nesse sentido, pode-se deduzir que houve negligência, tecida na interseção das condições concretas de existência e da dinâmica familiar. No caso de $D$, há um retorno para casa, porém a convivência com a mãe e o padrasto indicam que o adolescente acaba por assumir um papel de responsável pelas atividades domésticas. Percebe-se uma fragilidade na posição de filho e uma ênfase na de prestador de serviços. Os adolescentes se encontram em uma situação bastante instável, sem garantia de continuidade afetiva e sem o incentivo ao estabelecimento de sua individualidade (Chagnon, 2012). Nesse contexto de constantes mudanças e instabilidades, não é possível a construção de laços afetivos e vínculos que possam permitir a cada um separar-se dos demais e concentrar-se em si mesmos, tarefa primordial na construção identitária (Minuchin et al., 2009; Oliver, 2007; Rodgers, \& McGuire, 2012). Questiona-se como um contexto familiar configurado dessa forma pode prover as condições para que os adolescentes desenvolvam e expressem sua sexualidade normalmente, visto que para tal são necessárias orientação e educação oferecida por adultos (Costa, \& Costa, 2014). Este ponto torna-se fundamental no caso de condutas violentas de ordem sexual (Chagnon, 2012).

Em um dos casos, houve um estupro coletivo no banheiro da escola, o que facilita a hipótese de que o adolescente $A$ tenha se valido de uma situação na qual se encontrava amparado por outros adolescentes, sendo desse modo, autor também da violência. Sobre o adolescente $B$, também é mencionada a presença dele no banheiro da escola em situação suspeita. Essas circunstâncias de ambiente coletivo são facilitadoras de surgimento de violências nas quais os autores podem se diluir no coletivo, dispersar a responsabilidade e não ser identificados. Os comportamentos continuam sendo pedidos de ajuda, porém são sinalizadores de condições de repressão sexual que os adolescentes sofrem, por parte dos familiares. Assim, os atos cometidos pelos adolescentes funcionam como uma "válvula de escape" de um ambiente familiar que cerceia, e às vezes até ignora o desabrochar da sexualidade (Costa, \& Costa, 2013; 2014; Oliver, 2007). Essas observações apontam para uma repetição de violências que não foram, na ocasião e nem posteriormente, significadas como violências, sendo que isso permite que o sofrimento seja desqualificado e visto como naturalizado. Nesse sentido, a violência não tem alternativa a não ser se mostrar mais e mais exacerbada, comparecendo como um pedido de socorro, uma tentativa de interrupção do ciclo de sofrimentos (Conceição et al., 2014; Turner et al., 2016). Os estudos sobre os adolescentes que cometeram ofensa sexual têm centrado atenção na experiência de vitimização e abandono que esses adolescentes sofreram durante sua curta vida (Letourneau, \& Miner, 2005; Marshall, 2001; Oliver, 2007; Rodgers, \& McGuire, 2012; Roman, 2012). Novamente observa-se a repetição do mesmo padrão entre os adolescentes desta pesquisa.

\section{Núcleo de sentido 3 - Pais ausentes e mães dominadoras sem investimento afetivo no adolescente}

As histórias familiares indicam ainda que os pais são alcoolistas, "mulherengos" e não têm contato com os filhos. Observa-se que mesmo os adolescentes que moram com os padrastos possuem uma relação hostil com eles. Essas situações nos levam a questionar como esses adolescentes desenvolverão processos de identificação a respeito da sua condição masculina. Outro ponto fundamental para a eclosão da violência sexual é a questão do investimento afetivo emocional das mães com esses adolescentes. Observa-se que, no caso do $D$, a expectativa da mãe é pelo seu não crescimento e autonomia, quando ele é mantido dentro de casa, em uma situação mais ou menos de impedimento de saída, em função das atividades domésticas desenvolvidas por conta da ausência materna, já que a mãe dorme a maior parte do tempo. No caso de $B$, parece não existir envolvimento afetivo com a mãe; o que se observa é a negligência, quase que um ignorar da existência desse filho como sujeito. $B$ se tornou apenas uma "coisa" que dá muito trabalho. Para $A$ também não há um projeto de aproximação de sua mãe, e sim um interesse da avó, sendo que o mesmo também ocorre em relação a $C$.

Em outras palavras, a relação que as mães estabelecem com esses adolescentes é uma relação desprovida do reconhecimento de alteridade (Araújo, 2001). Os filhos são objetivados como posses sobre as quais se exerce a dominação, com imposição da realização 
de atividades domésticas exaustivas como forma de desviar e canalizar toda a energia libidinal em ebulição e também de assumirem obrigações de "mãe e cuidadora". Pode-se compreender que esses adolescentes apresentem condutas de raiva e ódio, pois possuem percepção de não serem protegidos e serem desrespeitados em sua autonomia em desabrochar (Costa, \& Costa, 2014; Minuchin et al., 2009).

Um aspecto chave no desenvolvimento dos adolescentes diz respeito à dimensão de confiança, que é uma experiência vinculada às relações parentais, da infância à juventude, e se expressa nas relações futuras desse adolescente. O padrão de sensibilidade e qualidade da vinculação afetiva está associado à confiança nas relações. Ofensores sexuais, tanto adultos como adolescentes, estiveram expostos a relações violentas em seu desenvolvimento e, por tal motivo, a confiança nas relações afetivas e a aceitação social não foram uma constante em suas vidas (Bogaerts et al., 2010; Costa et al., 2013; Marshall, 2001). Todos os adolescentes desta pesquisa mantêm relações problemáticas com seus pais, ou com seus cuidadores ao longo da vida. A presença de conflitos afetivos nas gerações ajuda na compreensão de que provavelmente os pais também não vivenciaram satisfação e confiança em suas próprias vivências de vinculações. Percebe-se uma falta de interesse por parte das mães e dos pais marcando a experiência de vida dos adolescentes.

\section{Núcleo de sentido 4 - A transmissão geracional}

A visualização dos genogramas aponta, em comum, a existência de: rompimentos de laços afetivos familiares bruscos, crianças mortas na infância ou natimortas, violência, alcoolismo de pais e padrastos, relações conflituosas, abandono de filhos, possíveis patologias que necessitam investigação mais acurada. Agrega-se, ainda, uma grande quantidade de filhos em cada geração em famílias que empreenderam processo de migração de cidades distantes em direção a capitais de grande porte, com o fito de melhoria de vida, mas que resultaram em dificuldades de adaptação, bem como de empobrecimento (Costa et al., 2013). Ainda em relação a essa constatação, é necessário apontar o baixo rendimento econômico familiar. Todos os adolescentes pertencem a famílias que percebem de dois a cinco salários mínimos. Isso, sem dúvida, traz uma característica comum que se traduz por um contexto caracterizado por pouco acesso a recursos ambientais como saúde, estabilidade financeira, oportunidades de boa escolarização (Spilbury, \& Korbin, 2013).

Observam-se relações amorosas fortuitas que geram várias separações, mas que deixam frutos com o nascimento de crianças em cada uma das uniões. A geração anterior dos avós foi quem acabou por cuidar dos adolescentes. As histórias das famílias envolvem sofrimento de várias violências nas gerações anteriores à do adolescente, em especial o sofrimento das mães, quando se sabe que tiveram gestações ainda na adolescência, maternidade precoce, foram empregadas domésticas em idade infantil, tiveram experiências de abandono com saídas de casa e foram vítimas de negligência. Nota-se que esses aspectos estão ligados à indicação dada pela visualização do genograma de que o núcleo de decisão sobre o adolescente é mais amplo do que o conjunto parental, incluindo várias pessoas. Isso pode ser um fator de risco, pois traz confusão sobre quem é, de fato, responsável por ele.

A descrição dessas condições tem sido amplamente divulgada por autores nacionais como um contexto de construção de atos infracionais e do uso da violência como forma de comunicação de um pedido de ajuda do adolescente frente a essas adversidades (Cairus, Conceição, \& Sudbrack, 2010; Penso, Ocampos, \& Lordello, 2012). Por outro lado, autores internacionais concordam e se voltam às condições de avaliação das características do meio ambiente no oferecimento de riscos que envolvem também a família (Lauritsen, \& Carbone-Lopez, 2011; Rodgers, \& McGuire, 2012; Zankman, \& Bonomo, 2004). Em uma perspectiva de transmissão geracional, essas mães também viveram situações de violência e anulação de sua condição de sujeito. Existem muitos conflitos apontados entre as mães e seus filhos, assim como conflitos entre vários membros das famílias em uma mesma geração.

Uma observação cuidadosa do genograma nos leva à constatação de que essas relações coisificadas são padrões transgeracionais que se repetem nas vidas desses adolescentes pela via violenta da prática de abusos sexuais e outras violências. Aqui se trata de repetições ao longo de gerações. Essa constatação enfoca o tema da polivitimização que trata das vitimizações continuadas e repetidas ao longo do tempo. Polivitimização é o acúmulo de vitimizações que se repetem ao longo de etapa de desen- 
volvimento na infância, tais como abuso físico, abuso emocional, exposição à violência doméstica. O estudo da polivitimização, na temática da violência sexual, é muito revelador do grau de dano à pessoa, visto que o abuso sexual, principalmente o intrafamiliar, tende a ficar encoberto por mais tempo e, portanto, desconhecido (Turner et al., 2016). A tendência atual de enfoque desse estudo é sobre o contexto, ou seja, a vítima, o vitimizador e as circunstâncias da vitimização. Esse aspecto interessa sobremaneira à presente discussão, pois o que está em questão é uma criança vitimizada por um adolescente vitimizado também, pertencentes a famílias com membros vitimizados, constituindo-se em um padrão transgeracional de múltiplas vitimizações (Finkelhor et al., 2009; Turner et al., 2016).

\section{Considerações finais}

Em razão do exposto, uma proposta de intervenção com o adolescente que cometeu ato infracional de natureza sexual não pode prescindir da presença da família como protagonista. O conhecimento do funcionamento psíquico, emocional e social desse adolescente é tão fundamental quanto o conhecimento da dinâmica familiar. O uso do genograma acrescenta informações sobre a repetição do padrão de violência mediando os conflitos ao longo de várias gerações, ampliando um olhar sobre o significado do ato do adolescente. Desse modo, o reconhecimento por vários membros da família de suas vitimizações oferece oportunidades para maior compreensão do adolescente, assim como a igualização de condições semelhantes de vitimização. Chama a atenção a presença de dois fatos preponderantes para o surgimento de atos violentos praticados por adolescentes: a falta de supervisão parental e o consequente abandono afetivo, assim como conflitos intergeracionais. Esses aspectos constituem-se em contexto de risco na opinião de várias referências sobre o tema da ofensa sexual praticada por adolescentes (Chagnon, 2012; Lansford et al., 2007; Marshall, 2001; Oliver, 2007; Turner et al., 2016; Zankman, \& Bonomo, 2004).

$\mathrm{O}$ instrumento mostrou-se um valioso tanto como recurso diagnóstico como de intervenção clínica, na medida em que explicitou a missão da família, carregada de uma geração a outra, que se traduz no legado da "trans-missão" geracional. No manejo da intervenção, cabe ao psicólogo situar a influência do cenário psicossociológico mais amplo para que não se omita a responsabilização da violência estrutural e que não se perpetue a tendência de criminalização da pobreza. O limite do texto diz respeito às dificuldades de as famílias recuperarem as histórias familiares. Parece não haver uma valorização de certas memórias, ou quiçá, haja um desejo deliberado de não trazer tais histórias à tona, pois as famílias se queixam do sofrimento que a narrativa traz para todos.

\section{Referências}

Almeida, M. E., Magalhães, A. S., \& Féres-Carneiro, T. (2014). Transmissão geracional da profissão na família: repetição e diferenciação. Psico, 45(4), 454-462. Recuperado de http://revistaseletronicas.pucrs.br/ojs/index.php/ revistapsico/article/view/15344/12472

Araújo, J. N. G. (2001). Função paterna e constituição dos grupos sociais. In J. N. G. Araújo, G. Souki, \& C. A. P. Faria (Eds.), Figura paterna e ordem social. Tutela, autoridade e legitimidade nas sociedades contemporâneas (pp. 17-28). Belo Horizonte, MG: Autêntica.

Barreto, A. C., Bucher-Maluschke, J. S. N. F., Almeida, P. C., \& Souza, E. (2009). Desenvolvimento humano e violência de gênero: uma integração bioecológica. Psicologia: Reflexão e Crítica, 22(1), 86-92. https:// doi.org/10.1590/S0102-79722009000100012

Bogaerts, S., Buschman, J., Kunst, M. J. J., \& Winkel, F. W. (2010). Intra-and extra-familial child molestation and personality disorders. International Journal of Offender Therapy and Comparative Criminology, 54(4), 478-493. https:// doi.org/10.1177/0306624X09334519

Boszormenyi-Nagy, I., \& Spark, G. M. (2001). Lealdades invisibles (I. Pardal, trad.). Buenos Aires: Amorrortu.

Bowen, M. (1991). De la familia al individuo. Buenos Aires: Paidós.

Brasil. (1990, 16 de julho). Lei No 8.069, de 13 de julho de 1990. Dispõe sobre Estatuto da Criança e do Adolescente e dá outras providências. Diário Oficial da União. 
Cairus, R. C. R., Conceição, M. I. G., \& Sudbrack, M. F. O. (2010). A questão psicossocial da proteção e do risco de crianças e adolescentes. In D. M. Amparo, S. F. C. Almeida, K. T. R. Brasil \& F. Marty (Eds.), Adolescência e violência. Teorias e práticas nos campos clínico, educacional e jurídico (pp. 253-279). Brasília, DF: Liber.

Cenci, C. M. B., Teixeira, J. F., \& Oliveira, L. R. F. (2014). Lealdades invisíveis: coparticipação da família no ato infracional. Pensando Famílias, 18(1), 35-44. Recuperado de http://pepsic.bvsalud.org/scielo.php?script=sci_arttext\&pid=S1679-494X2014000100004

Chagnon, J.-I. (2012). As agressões sexuais na adolescência. In D. M. Amparo, S. F. C. Almeida, K. T. R. Brasil, M. I. G. Conceição, \& F. Marty (Eds.), Adolescência e violência: intervenções e estudos clínicos, psicossociais e educacionais (pp. 57-77). Brasília, DF: Liber.

Conceição, M. I. G., Penso, M. A., Costa, L. F., \& Carreteiro, T. C. O. C. (2014). Relação pai-filho em adolescentes que cometeram ato infracional de natureza sexual e social. Revista de Direito da Infância e da Juventude, 2(3), 237 -252.

Correa, O. B. R. (Ed.) (2000). Os avatares da transmissão psíquica geracional. São Paulo, SP: Escuta.

Costa, B. N. S., \& Costa, L. F. (2013). Perpetrador e vítima: o adolescente que cometeu ofensa sexual. Revista Latinoamericana de Ciencias Sociales, Niñez y Juventud, 11(2), 855-869. Recuperado de http://www.scielo.org.co/pdf/ rlcs/v1ln2/v1ln2a13.pdf

Costa, B. N. S., \& Costa, L. F. (2014). Relações familiares violentas do adolescente que cometeu ofensa sexual. Revista de Criminologia e Ciências Penitenciárias, 3(4). Recuperado de http://sospsiquiatria.com/newsite/index. $\mathrm{php} / \mathrm{COPEN} /$ article/view/248/378

Costa, F. A. O., Costa, L. F., \& Conceição, M. I. G. (2014). O adolescente que cometeu abuso sexual extrafamiliar: motivação e sofrimento. Revista Subjetividades, 14(1), 97-106. Recuperado de http://pepsic.bvsalud.org/pdf/rs/ v14n1/09.pdf

Costa, L. F., Junqueira, E. L., Meneses, F. F. F., \& Stroher, L. M. (2013). As relações familiares do adolescente ofensor sexual. Psico USF, 18(1), 33-44. Recuperado de http://www.redalyc.org/articulo.oa?id=401036093005

Costa, L. F., Marreco, D. F., Barros, J. F., \& Chaves, M. N. S. G. (2015). Meninos pré-adolescentes que abusam sexualmente de meninos. Acta Psiquiátrica y Psicológica de America Latina, 61(1), 80-88.

Finkelhor, D., Ormrod, R. K., Turner, H. A., \& Holt, M. (2009). Pathways to poly-victimzation. Child Maltreatment, 14(4), 316-329. https://doi.org/10.1177/1077559509347012

Gaulejac, V., Marquez, S. R., \& Ruiz, E. T. (2005). História de vida: psicoanálisis y sociologia clínica. México, DF: Universidad Autónoma de Querétaro.

Instituto Brasileiro de Geografia e Estatística - IBGE. (2015). IBGE divulga renda familiar per capita 2015. Recuperado de ftp://ftp.ibge.gov.br/Trabalho_e_Rendimento/Pesquisa_Nacional_por_Amostra_de_Domicilios_continua/Renda_domiciliar_per_capita/Renda_domiciliar_per_capita_2015_20160420.pdf

Lansford, J. E., Miller-Johnson, S., Berlin, L. J., Dodge, K. A., Bates, J. E., \& Pettit, G. S. (2007). Early physical abuse and later violent delinquency: A prospective longitudinal study. Child Maltreatment, 12(3), 233-245. https://doi.org/10.1177/1077559507301841

Lauritsen, J. L., \& Carbone-Lopez, K. (2011). Gender differences in risk factors for violent victimization: An examination of individual-, family-, and community-level predictors. Journal of Research in Crime and Delinquency, 48(4), 538-565. https://doi.org/10.1177/0022427810395356

Letourneau, E. J., \& Miner, M. H. (2005). Juvenile sex offenders: a case against the legal and clinical status quo. Sex Abuse, 17(3), 293-312. https://doi.org/10.1177/107906320501700304.

Machado, M.T. (2003). A proteção constitucional de crianças e adolescentes e dos direitos humanos. Barueri, SP: Manole.

Marshall, W. L. (2001). Agresores sexuales. Barcelona: Ariel.

McGoldrick, M., Gerson, R., \& Petry, S. (2012). Genograma: avaliação e intervenção familiar (3a ed.). Porto Alegre, RS: Artmed.

Meneses, F. F. F., Stroher, L. M. C., Setubal, C. B., Wolff, L. S., \& Costa, L. F. (2016). Intervenção psicossocial com o adulto autor de violência sexual intrafamiliar contra crianças e adolescentes. Contextos Clínicos, 9(1), 98-108. https://doi.org/10.4013/ctc.2016.91.08

Minayo, M. C. S. (1996). O desafio do conhecimento: pesquisa qualitativa em saúde. São Paulo, SP: Hucitec. 
Minuchin, S., Nichols, M. P., \& Lee, W-Y. (2009). Famílias e casais: do sintoma ao sistema. Porto Alegre, RS: Artmed.

Neuburger, R. (1997). La familia dolorosa: mitos y terapias familiares. Barcelona: Herder.

Oliver, B. E. (2007). Three steps to reducing child molestation by adolescents. Child Abuse \& Neglect, 31(7), 683-689. https://doi.org/10.1016/j.chiabu.2006.09.008

Penso, M. A., Conceição, M. I. G., Costa, L. F., \& Carreteiro, T. C. O. C. (2012). Jovens pedem socorro: o adolescente que praticou ato infracional e o adolescente que cometeu ofensa sexual. Brasília, DF: Liber.

Penso, M. A., Costa, L. F., Conceição, M. I. G., \& Carreteiro, T. C. O. (2013). As mães dos adolescentes que cometeram ato infracional social e de natureza sexual. Interacções, 9(25), p. 151-179. Retrieved from http:// revistas.rcaap.pt/ interaccoes/article/view/2856/2361

Penso, M. A., Ocampos, D. L., \& Lordello, S. R. (2012). A prevenção da violência: políticas públicas de saúde para adolescentes. In D. M. Amparo, S. F. C. Almeida, K. T. R. Brasil, M. I. G. Conceição, \& F. Marty (Eds.), Adolescência e violência: intervenções e estudos clínicos, psicossociais e educacionais (pp. 357-377). Brasília, DF: Liber.

Penso, M. A., \& Costa, L. F. (2017). Perspectiva sistêmica de intervenção na violência contra crianças e adolescentes. In R. Payá (Ed.), Intercâmbios das psicoterapias: como cada abordagem psicoterapêutica compreende os transtornos psiquiátricos (2a ed., p. 669-676). São Paulo, SP: GEN/ROCA.

Pincolini, A. M. F., \& Hutz, C. S. (2014). Abusadores sexuais adultos e adolescentes no sul do Brasil: pesquisa em denúncias e sentenças judiciais. Temas em Psicologia, 22(2), 301-311. https://doi.org/10.9788/TP2014.2-03

Rodgers, K. B., \& McGuire, J. K. (2012). Adolescent sexual risk and multiple contexts: interpersonal violence, parenting, and poverty. Journal of Interpersonal Violence, 27(11), 2091-2107. https://doi.org/10.1177/0886260511432148

Roman, P. (2012). Les Violences sexuelles à l'adolescence: comprendre, accueillir, prévenir. Paris: Elsevier Masson.

Salina, G. R. (2015). A transmissão da vida psíquica entre gerações: os aspectos determinantes do fazer-se herdeiro da violência sexual (Dissertação de mestrado). Universidade Estadual Paulista Júlio Mesquita, Araraquara, SP.

Santos, A. R., Marin, A. H., \& Castoldi, L. (2013). Percepção de mães e adolescentes sobre a violência intrafamiliar por meio da construção do genograma. Contextos Clínicos, 6(2), 174-184. https://doi.org/10.4013/ctc.2013.62.10

Spilbury, J. C., \& Korbin, J. E. (2013). Social networks and informal social support in protecting children from abuse and neglect. Child Abuse \& Neglect, 37S, 8-16. https://doi.org/10.1016/j.chiabu.2013.10.027

Turner, H. A., Shattuck, A., Finkelhor, D., \& Hamby, S. (2016). Polyvictimization and youth violence exposure across contexts. Journal of Adolescent Health, 58, 208-214. https://doi.org/10.1016/j.jadohealth.2015.09.021

Wilkinson, R., \& Pickett, K. (2010). The spirit level: why equality is better for everyone. London: Penguin.

Worley,K.B.,Church,J.K.,\&Clemmons,J.C. (2011).Parentsofadolescentswhocommittedsexualoffenses:characteristics, challenges, and interventions. Clinical Psychology, 17(3), 433-448.https://doi.org/10.1177/1359104511417787

Zankman, S., \& Bonomo, J. (2004). Working with parents to reduce juvenile sex offender recidivism. Journal of Child Sexual Abuse, 13(3/4), 139-156. https://doi.org/10.1300/J070v13n03_08

\section{Liana Fortunato Costa}

Universidade de Brasília, Brasília - DF. Brasil.

E-mail: lianaf@terra.com.br

\section{Maria Aparecida Penso}

Universidade Católica de Brasília, Brasília - DF. Brasil.

E-mail: mariaaparecidapenso@gmail.com

\section{Maria Inês Gandolfo Conceição}

Universidade de Brasília, Brasília - DF. Brasil.

E-mail: inesgandolfo@gmail.com 


\section{Teresa Cristina Othênio Cordeiro Carreteiro}

Universidade Federal Fluminense, Niterói - RJ, Brasil.

E-mail: tecar2@uol.com.br

Endereço para envio de correspondência:

Rua 08, Chácara 214, casa 17. Vicente Pires - Distrito Federal. CEP: 72.007 - 010

Recebido 12/12/2016

Revisado 16/07/2017

Aprovado 17/10/2017

Received 12/12/2016

Reformulated $07 / 16 / 2017$

Approved 10/17/2017

Recibido 12/12/2016

Reformulado 16/07/2017

Aceptado 17/10/2017

Como citar: Costa, L. F., Penso, M. A., Conceição, M. I. G., \& Carreteiro, T. C. O. (2017). Transmissão geracional familiar em adolescentes que cometeram ofensa sexual. Psicologia: Ciência e Profissão, 37(4), 995-1010. https://doi.org/10.1590/1982-3703004722016

How to cite: Costa, L. F., Penso, M. A., Conceição, M. I. G., \& Carreteiro, T. C. O. (2017). A family generational transmission in adolescents who committed sexual offense. Psicologia: Ciência e Profissão, 37(4), 995-1010. https://doi.org/10.1590/1982-3703004722016

Cómo citar: Costa, L. F., Penso, M. A., Conceição, M. I. G., \& Carreteiro, T. C. O. (2017). Transmisión generacional familiar en adolescentes que cometieron ofensa sexual. Psicologia: Ciência e Profissão, 37(4), 995-1010. https://doi.org/10.1590/1982-3703004722016 